\title{
Is N-terminal pro-brain type natriuretic peptide a useful marker in newborns with heart defects?
}

\author{
Agata Tarkowska ${ }^{A-D, F}$, Wanda Furmaga-Jabłońska ${ }^{A, C, E, F}$ \\ Department of Neonate and Infant Pathology, Medical University of Lublin, Poland \\ A - research concept and design; $\mathrm{B}$ - collection and/or assembly of data; $\mathrm{C}$ - data analysis and interpretation; \\ $D$ - writing the article; $E$ - critical revision of the article; $F$ - final approval of the article
}

Address for correspondence

Agata Tarkowska

agatatarkowska@umlub.pl

Funding sources

None declared

Conflict of interest

None declared

Received on September 27, 2020

Reviewed on November 1,2020

Accepted on December 17, 2020

Published online on July 30, 2021

Cite as

Tarkowska A, Furmaga-Jabłońska W. Is N-terminal pro-brain type natriuretic peptide a useful marker in newborns with heart defects? Adv Clin Exp Med. 2021;30(9):905-912. doi:10.17219/acem/131746

DOI

10.17219/acem/131746

Copyright

Copyright by Author(s)

This is an article distributed under the terms of the

Creative Commons Attribution 3.0 Unported (CC BY 3.0)

(https://creativecommons.org/licenses/by/3.0/)

\begin{abstract}
Background. Heart diseases are currently a significant cause of morbidity and mortality in newborns. The existing diagnostic methods are often not sufficient or, in many cases, cannot be used. Great advances have been achieved in medical knowledge concerning biomarkers for the diagnosis of circulatory system disorders in adult patients. Among these biomarkers, N-terminal pro-brain type natriuretic peptide (NT-proBNP) plays a main role. However, in the existing literature, there is not enough data concerning the physiological features of this biomarker in newborns and its potential use in neonatal cardiac diagnostics.
\end{abstract}

Objectives. To evaluate the diagnostic usefulness of NT-proBNP measurements in correlation with other markers of circulatory failure and myocardial damage in newborns with heart defects.

Materials and methods. This study involved 126 newborns. Patients were divided into 2 main groups: group I included infants with congenital heart defects (CHD) and group II (control) included healthy neonates. Newborns with CHD were further divided into 2 subgroups: group la with simple shunts and group lb with combined heart defects. Patients in group I were further divided according to the hemodynamic significance of CHD. The NT-proBNP level was evaluated using the CARDIAC proBNP immunologic test (Cobas h232; Roche Diagnostics, Basel, Switzerland).

Results. The NT-proBNP concentrations were significantly higher in newborns with CHD compared to healthy ones. Newborns with combined heart defects had higher levels of NT-proBNP than newborns with simple shunts. The NT-proBNP concentrations in newborns with CHD correlated with echocardiographic parameters of hemodynamic significance and with left ventricular ejection fraction (LVEF). Additionally, NT-proBNP correlated with clinical symptoms of heart failure (HF; Ross classification, Reithmann's score).

Conclusions. Statistically significant differences in NT-proBNP level between newborns with heart defects and healthy controls were shown. In newborns with heart diseases, significant correlations were found between NT-proBNP level and the type of heart defect (simple shunt or combined defects), the hemodynamic significance of the defect, LVEF, and the clinical intensity of HF.

Key words: congenital heart defects, biomarkers, newborns, NT-proBNP 


\section{Background}

Congenital heart defects (CHD) continue to represent a significant diagnostic and therapeutic challenge in newborns. ${ }^{1}$ Regarding the specificity of hemodynamic changes during the neonatal period, even serious life-threatening defects may initially appear as non-characteristic, oligosymptomatic diseases. The diagnostic methods currently available are often insufficient or cannot be used in infants due to the limited approach. ${ }^{2}$

Regarding the diagnostic procedures for circulatory system disorders in adults, biochemical markers of heart failure (HF) represent an important tool of unquestionable significance. Among them, brain natriuretic peptide (BNP) and its N-terminal prohormone (NT-proBNP) play key roles. ${ }^{3}$ The abovementioned biomarkers might prove to be highly useful in neonatal patients as well. ${ }^{4-6}$ However, data concerning adult patients cannot be directly applied to pediatric populations. The clinical value of these markers must be evaluated separately for every age group before applying them in practice. $^{5}$

The BNP is a neurohormone of cardiac origin secreted by the ventricular myocardium in response to increased heart wall tension due to volume and pressure overload, enhanced left ventricle (LV) mass, and a decreased shortening and ejection fraction (SF and EF). ${ }^{4,6}$ Natriuretic hormones are synthesized as preprohormones, and both BNP and NT-proBNP can be found in serum. Comparative studies show good correlation of the serum concentrations of both of these hormones. ${ }^{7}$

Concentrations of BNP and NT-proBNP depend on ventricle overload and increase together with the degree of LV dysfunction. At the same time, elevated NT-proBNP may indicate a preclinical stage of HF. ${ }^{8}$

Serum NT-proBNP is strictly connected with left ventricular ejection fraction (LVEF) and SF, and thus enables detection of their decreases with high diagnostic sensitivity and specificity. ${ }^{8}$ In patients with CHD, NT-proBNP is assumed to depend on pressure and volume overload. ${ }^{9}$ As of yet, no other serum biomarkers are known to indicate HF.

The essence of our project was to search for the least invasive, yet the most sensitive and specific, biomarker that will enable a more complete diagnosis of circulatory system conditions in newborns with cardiac problems. No biochemical markers of neonatal circulatory failure are in routine use yet, and the only potential marker currently known is BNF.

\section{Objectives}

The aim of this study was to evaluate the diagnostic usefulness of NT-proBNP measurements in correlation with other markers of circulatory failure in newborns with heart defects. We hope that, in the end, the obtained results and conclusions drawn will allow us to state whether the assessed markers are good diagnostic tools for the abovementioned cardiological problems of the neonatal period and whether they should be routinely used for the assessment of circulatory failure in newborns with heart defects.

\section{Materials and methods}

\section{Study design}

This study was designed to determine whether the concentration of NT-proBNP in the serum of newborns with CHD is statistically significantly higher than in the control group, and whether the concentration of NT-proBNP is significantly related to the following factors: the type and severity of the defect, the stage of HF assessed on the basis of clinical symptoms, and echocardiographic exponents.

Based on the obtained results, an attempt was made to initially assess whether this indicator is sensitive and specific enough to be used for the detection of pre-symptomatic circulatory failure in newborns.

The study group included patients born in the Lublin Voivodeship (a province of Poland) and hospitalized in the Department of Neonate and Infant Pathology (control group) and in the Department of Pediatric Cardiology (patients with CHD) of the University Children's Hospital of Lublin, Poland.

The study included a total of 126 infants divided into 2 main groups: group I (67 patients with CHD) and group II (control group, 59 healthy infants). As some of the patients were preterm infants, we used both chronological and postmenstrual age for the analysis. The characteristics of the included infants are shown in Table 1.

Table 1. Characteristics of the studied group. Number of patients: 126 (69 boys and 57 girls)

\begin{tabular}{|l|c|c|c|}
\multicolumn{1}{|c|}{ Variable } & Minimum & Maximum & Mean \\
\hline Gestational age & 25 weeks & 42 weeks & 38 weeks \\
\hline Chronological age & 6 days & 135 days & 21 days \\
\hline Postmenstrual age & 34 weeks & 46 weeks & 41 weeks \\
\hline Birth weight & $585 \mathrm{~g}$ & $5400 \mathrm{~g}$ & $3137 \mathrm{~g}$ \\
\hline
\end{tabular}

Patients with a history of perinatal asphyxia or with severe conditions other than CHD were not included in the study.

The study protocol was approved by the Ethics Committee of Medical University of Lublin. All participants' legal guardians have signed the informed consent.

\section{Variables and data sources}

All included infants underwent echocardiographic evaluation with LV SF assessment with flow assessment (continuous wave Doppler) and flow visualization using color 
Table 2. Characteristics of heart defects in group I

\begin{tabular}{|c|c|c|c|c|}
\hline \multicolumn{3}{|c|}{ Division of heart defects } & Type of defect & Number of patients \\
\hline \multirow{18}{*}{$\begin{array}{l}\text { Patients with } \\
\text { congenital heart } \\
\text { defects } \\
\text { (group I) } \\
n=67\end{array}$} & \multirow{13}{*}{$\begin{array}{c}\text { significant } \\
\text { hemodynamic } \\
\text { defects (group li) } \\
n=38\end{array}$} & \multirow{5}{*}{$\begin{array}{l}\text { simple shunts } \\
\text { (group la) } \\
n=21\end{array}$} & ASD+VSD & 12 \\
\hline & & & ASD+VSD+PDA & 4 \\
\hline & & & ASD+PDA & 3 \\
\hline & & & PDA & 1 \\
\hline & & & ASD & 1 \\
\hline & & \multirow{8}{*}{$\begin{array}{l}\text { combined heart defects } \\
\qquad \begin{array}{c}\text { (group } \mathrm{lb} \text { ) } \\
\mathrm{n}=17\end{array}\end{array}$} & CAVC & 6 \\
\hline & & & FT4 & 3 \\
\hline & & & $P S+A S D$ & 2 \\
\hline & & & $\mathrm{COA}+\mathrm{ASD}$ & 2 \\
\hline & & & TA & 1 \\
\hline & & & L-TGA+VSD+PS & 1 \\
\hline & & & DORV+ASD & 1 \\
\hline & & & $S A+P S+A S D+P D A$ & 1 \\
\hline & \multirow{5}{*}{$\begin{array}{l}\text { defects without } \\
\text { hemodynamic } \\
\text { significance } \\
\text { (group In) } \\
n=29\end{array}$} & \multirow{4}{*}{$\begin{array}{l}\text { simple shunts } \\
\text { (group la) } \\
n=28\end{array}$} & ASD & 12 \\
\hline & & & ASD+PDA & 8 \\
\hline & & & ASD+VSD & 5 \\
\hline & & & $\mathrm{ASD}+\mathrm{VSD}+\mathrm{PDA}$ & 3 \\
\hline & & $\begin{array}{l}\text { combined heart defects } \\
\text { (group } \mathrm{lb}) \\
n=1\end{array}$ & $P S+A S D$ & 1 \\
\hline
\end{tabular}

n - number of patients; ASD - atrial septum defect; VSD - ventricular septum defect; PDA - persistent ductus arteriosus; CoA - aortic coarctation;

PS - pulmonary stenosis; DORV - double outlet right ventricle; TA - truncus arteriosus; TGA - transposition of great arteries; SA - aortic stenosis.

Doppler. Echocardiographic examination was performed according to standard protocol with the use of a SEQUOIA C256 device and Acuson 7v3c probe (frequency 3-7 MHz) (Siemens AG, Munich, Germany). The SF was calculated on the basis of the following formula:

$$
\mathrm{SF}=[(\mathrm{LVDd}-\mathrm{LVSd}) / \mathrm{LVDd}] \times 100 \%,
$$

where LVSd - LV systolic diameter and LVDd - LV diastolic diameter, both measured in one-dimensional $\mathrm{M}$ mode registration. Newborns from group I were subsequently divided in 2 ways. First, 2 subgroups were formed according to the type of heart defect: group Ia with simple shunts and group IIb with combined heart defects. Group Ia consisted of 49 patients. The following defects were diagnosed in this group: atrial septum defect (ASD, 13 cases), persistent ductus arteriosus (PDA, 1 case), or coexistence of 2 or 3 shunts, 35 cases: (ASD+VSD, 17 cases), (ASD+PA, 11 cases), (ASD+VSD+PDA, 7 cases). Eighteen newborns were assigned to group IIb. The following defects were diagnosed in this group: common atrioventricular canal (CAVC, 6 cases), tetralogy of Fallot (TOF, 3 cases), pulmonary stenosis (PS) with ASD (3 cases), aortic coarctation (CoA, 2 cases), truncus arteriosus (PTA, 1 case), levo-transposition of the great arteries (L-TGA) with PS and VSD (1 case), double outlet right ventricle (DORV) with ASD (1 case), and aortic stenosis (SA) with PS, ASD, and PDA (1 case).

Another subdivision was formed based on echocardiographic parameters of hemodynamic significance: group Ii included patients with hemodynamically significant CHD, while group In included patients presenting with hemodynamically non-significant heart defects. Group Ii consisted of 38 patients and group In consisted of 29 patients.

The results of the echocardiographic assessment are summarized in Table 2.

Additionally, all patients underwent clinical evaluation for the presence and severity of HF signs and symptoms. Both Ross classification for heart failure in children ${ }^{11,12}$ and Reithmann's pediatric heart failure score ${ }^{13}$ were applied independently for each studied newborn. The comparison of echocardiographic evaluation and clinical HF scoring results is presented in Table 3.

The NT-proBNP concentrations were evaluated with the Roche CARDIAC proBNP immunologic test using a Cobas h232 system (Roche Diagnostics, Basel, Switzerland). The newborns in the control group were considered healthy; however, some might have clinically silent CHD.

Table 3. Comparison of echocardiographic evaluation and clinical heart failure scoring in group I

\begin{tabular}{|l|c|c|}
$\begin{array}{c}\text { Hemodynamic } \\
\text { significance of CHD } \\
\text { (evaluated with ECHO) }\end{array}$ & $\begin{array}{c}\text { The Ross } \\
\text { classification score } \\
\text { (mean and SD) }\end{array}$ & $\begin{array}{c}\text { The Reithmann } \\
\text { classification score } \\
\text { (mean and SD) }\end{array}$ \\
\hline Significant $(\mathrm{n}=38)$ & $1.53 \pm 1.01$ & $1.34 \pm 2.22$ \\
\hline Nonsignificant $(\mathrm{n}=29)$ & $1 \pm 0$ & $0.11 \pm 0.42$ \\
\hline
\end{tabular}

CHD - congenital heart defect; SD - standard deviation. 
To eliminate this potential bias, all patients from the control group underwent echocardiographic evaluation.

The number of relevant patients hospitalized in the departments during the study period determined the sample size.

We examined the association of clinical signs of HF in infants evaluated using 2 different classifications with the results of echocardiographic evaluation and NT-proBNP concentrations.

\section{Statistical analyses}

The obtained results, after checking the normality of the distribution, were statistically analyzed using the appropriate tests with STATISTICA v. 9.0 software (StatSoft Inc., Tulsa, USA). The right-handed asymmetry of certain distributions was eliminated by means of logarithmic transformation. Dependency analysis was performed based on Pearson's linear correlation coefficient (r) or Spearman's $(R)$ rank correlation test and t-tests of the significance of the correlation coefficient in the studied groups. The strength of association between 2 nominal variables was evaluated by the use of the Cramer's V coefficient. A p-value less than 0.05 ( $\mathrm{p}<0.05)$ was considered statistically significant.

\section{Results}

The analyses revealed that NT-proBNP levels in newborns with heart pathology were significantly higher than those in healthy infants. In the control group, the percentage of newborns with a NT-proBNP level $<1500 \mathrm{pg} / \mathrm{mL}$ was significantly higher than in the CHD group $(\mathrm{p}=0.0001)$. Moreover, there were no patients with NT-proBNP $>3000 \mathrm{pg} / \mathrm{mL}$ in group II. In group I, 37\% of patients presented such high levels ( $\mathrm{p}<0.0001$; Fig. 1, Table 4).

Among the CHD group, a significant correlation was observed concerning NT-proBNP and the type of heart defect: newborns with combined defects presented with

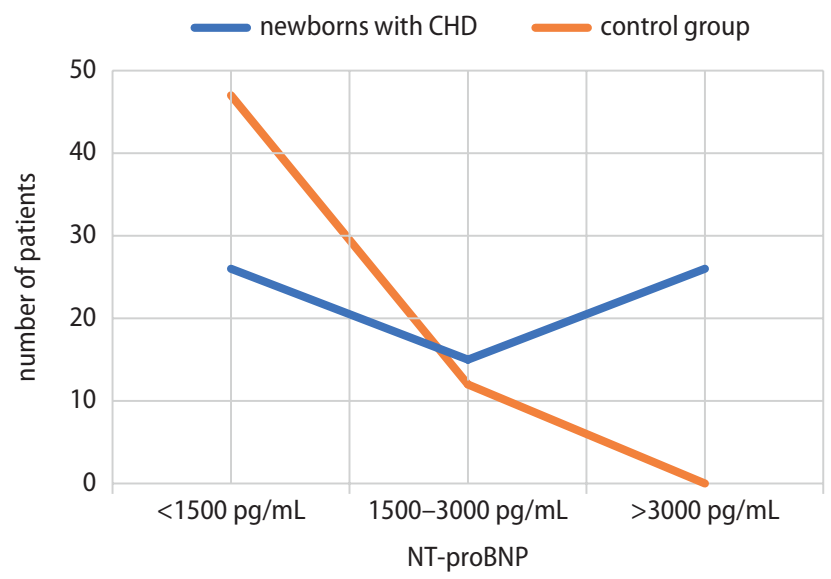

Fig. 1. NT-proBNP concentration ranges in the study groups. CHD - congenital heart defect; NT-pro BNP - N-terminal pro-brain type natriuretic peptide
Table 4. NT-proBNP concentration ranges in studied groups

\begin{tabular}{|l|c|c|}
$\begin{array}{c}\text { NT-proBNP } \\
{[\mathrm{pg} / \mathrm{mL}]}\end{array}$ & $\begin{array}{c}\text { Newborns with CHD } \\
\text { (group I) }(\mathrm{n}=67)\end{array}$ & $\begin{array}{c}\text { Control group (group II) } \\
(\mathrm{n}=59)\end{array}$ \\
\hline$<1500$ & 26 & 47 \\
$1500-3000$ & 15 & 12 \\
$>3000$ & 26 & 0 \\
\hline
\end{tabular}

CHD - congenital heart defect; NT-pro BNP - N-terminal pro-brain type natriuretic peptide.

Table 5. NT-proBNP concentration in relationship to the type of heart defect $(p=0.0004)$

\begin{tabular}{|l|c|c|}
$\begin{array}{c}\text { NT-proBNP } \\
{[\mathrm{pg} / \mathrm{mL}]}\end{array}$ & $\begin{array}{c}\text { Simple shuts } \\
(\mathrm{n}=49)\end{array}$ & $\begin{array}{c}\text { Combined CHD } \\
(\mathrm{n}=18)\end{array}$ \\
\hline$<1500$ & $25(50 \%)$ & $2(12 \%)$ \\
\hline $1500-3000$ & $13(27 \%)$ & $2(12 \%)$ \\
$>3000$ & $11(23 \%)$ & $14(76 \%)$ \\
\hline
\end{tabular}

CHD - congenital heart defect; NT-pro BNP - N-terminal pro-brain type natriuretic peptide.

Table 6. NT-proBNP concentration in relationship to heart defect hemodynamic significance

\begin{tabular}{|c|c|c|}
$\begin{array}{c}\text { NT-proBNP } \\
(\mathrm{pg} / \mathrm{mL})\end{array}$ & $\begin{array}{c}\text { Significant CHD } \\
\text { group li }(\mathrm{n}=38)\end{array}$ & $\begin{array}{c}\text { Non-significant CHD } \\
\text { group } \ln (\mathrm{n}=29)\end{array}$ \\
\hline$<1500$ & 4 & 23 \\
\hline $1500-3000$ & 10 & 5 \\
$>3000$ & 24 & 1 \\
\hline
\end{tabular}

CHD - congenital heart defect; NT-pro BNP - N-terminal pro-brain type natriuretic peptide.

higher NT-proBNP levels than those with simple shunts ( $\mathrm{p}=0.0004$; Table 5).

A significant correlation was also noted between NTproBNP and CHD hemodynamic significance evaluated with echocardiographic parameters $(\mathrm{p}<0.00001$, Cramer's V coefficient: $V=0.72$ ). The percentage of newborns with hemodynamically significant CHD increased with a higher NT-proBNP concentration (Table 6).

Moreover, a strong positive correlation was found between NT-proBNP concentration and severity of HF evaluated using the Ross classification for heart failure in children and Reithmann's pediatric heart failure score. Spearman's rank correlation coefficient for the Ross classification score and serum NT-proBNP was statistically significant $(R=0.347$, $\mathrm{p}=0.005$ ). An even stronger positive correlation was observed between Reithmann's heart failure score and NT-pro BNP concentration ( $\mathrm{R}=0.448, \mathrm{p}=0.0002)$. Therefore, the more severe the HF, the higher the NT-proBNP concentration.

\section{Discussion}

The BNP and NT-proBNP show high diagnostic accuracy for HF in adults. ${ }^{14-16}$ Moreover, they might be used as screening tools as well as markers of response 
to treatment and prognosis in asymptomatic adult patients with subclinical heart dysfunction. ${ }^{15,17,18}$ According to the literature, BNP and NT-proBNP levels are also elevated in children with heart diseases and can reflect functional efficiency in pediatric chronic HF. 4,10,19,20

Geiger et al. evaluated 102 pediatric patients aged 0-18 years with CHD and a control group of 65 healthy children. Their study revealed significant differences in NT-proBNP concentrations between children with heart diseases and healthy ones. Additionally, NT-proBNP level is influenced by the presence of clinical symptoms of HF. ${ }^{20}$ Similar results were obtained in a study by Mir et al. that aimed to evaluate NT-proBNP serum concentrations in healthy children as well as 31 children aged 1-14 months with clinical signs of HF. The NT-proBNP level was again significantly higher in children with HF than in healthy ones. Moreover, a positive correlation was observed between NT-proBNP level and scoring of clinical HF symptoms. However, the statistical significance depended on the type of pathology (shunts compared to combined defects and cardiomyopathies). ${ }^{4}$ A study by Nir et al. confirmed that the mean NT-proBNP serum concentration was higher in patients with hemodynamically significant heart pathologies compared to the control group. ${ }^{10}$ Their study compared NT-proBNP concentrations in 55 sick and 58 healthy children aged from 4 months to 15 years. The results were consistent with those of other studies. ${ }^{4,20}$ However, the abovementioned studies were conducted in older infants and children, and did not include a neonatal population. Our study revealed that, in newborns with CHD, NT-proBNP serum concentrations were significantly higher than in the control group. Our results are consistent with the data from the literature and confirm the findings of other researchers. ${ }^{21,22}$

Another study concerning newborns with CHD was published by Cantinotti et al. ${ }^{22}$ They evaluated BNP in 152 patients with CHD in the $1^{\text {st }}$ month of life (including 6 preterm infants) and 154 healthy neonates as the control group. Patients with CHD showed significantly higher BNP concentrations than healthy ones. Significant differences in BNP concentrations were also observed depending on heart disease characterization: the lowest BNP values were found in patients with right ventricle volume overload, whereas heart defects with LV overload were usually accompanied by higher BNP values. Although some generalizations were possible, BNP did not enable precise distinction between particular heart defects because of the high level of individual variation in concentrations, regardless of pathology type. The conclusion was that BNP could be a cardio-specific marker but is not specific to particular disease entities, which is in accordance with another study. ${ }^{23}$ However, our study revealed significant relationships between NT-proBNP and cardiac pathology type in newborns with heart defects. The difference between our results and previous studies probably results from the considerable homogeneity in our patient group.
Our study did not include patients with cardiomyopathies or structural disorders other than CHD. This enabled simple division into 2 groups: patients with isolated shunts and patients with combined heart defects. Among newborns with NT-proBNP level $>3000 \mathrm{pg} / \mathrm{mL}$, the percentage of patients with combined heart defects was significantly higher than the percentage of newborns with simple shunts. This result may have practical importance, as combined heart defects in newborns usually lead to serious clinical complications and a need for urgent cardiosurgical treatment.

Other researchers have reported elevated serum NTproBNP levels in children with CHD leading to a left to right shunt. ${ }^{4,10}$ In their study, Nir et al. included pediatric patients with heart defects resulting in significant hemodynamic effects. ${ }^{10}$ In the studied group, there were 13 patients with a left-to-right shunt. On the basis of this group, the authors revealed that patients with a high pressure leakage (VSD or PDA) presented higher NT-proBNP concentrations than patients with a low-pressure shunt (ASD). Kunii et al. estimated the possibility of using BNP to evaluate leakage significance in a group of 154 children with one of the following abnormalities: VSD, PDA or ASD. ${ }^{24}$ The BNP showed a correlation with the Qp:Qs ratio (Qp - pulmonary flow, Qs - systemic flow) for all 3 types of defects. In our study, no correlation was found between left-to-right shunt flow velocity and NT-proBNP concentration in patients with shunts. Similarly, no correlation was found concerning the defect diameter and NT-proBNP concentration. The lack of correlation was probably caused by allocating patients with high and low pressure defects to the same group. The second probable explanation is that some of the defects were hemodynamically insignificant. This explanation seems to be supported by another result - the highly significant correlation between NT-proBNP and hemodynamic significance of the shunt (evaluated on the basis of echocardiographic parameters).

The results of our study may have practical clinical significance, as newborns with inborn heart defects causing serious hemodynamic disturbances typically need urgent cardiologic consultation and treatment. Moreover, serial NT-proBNP measurements in newborns with heart defects may be useful for monitoring hemodynamic disturbances, which quite often increase rapidly in the adaptive period.

In the existing literature, there is limited data concerning the usefulness of the above peptides as markers of cyanotic and other combined heart defects. ${ }^{25}$ A study by Hopkins et al. revealed elevated NT-proBNP in 10 adults with cyanotic heart defects (including Eisenmenger's syndrome), despite the lack of increased pressure overload. ${ }^{26}$ A study by Koch et al., including 288 children with CHD (33 with TOF) and 152 healthy children in the control group, reported that BNP was not elevated in patients with TOF. ${ }^{5}$ The same study showed higher BNP levels in patients with a functional single ventricle compared to healthy children. To date, only a few studies have focused on newborns with severe combined heart defects. Lechner et al. 
conducted an interesting study to check if NT-proBNP levels in the cord blood of newborns with CHD were elevated compared to healthy neonates. ${ }^{27}$ The study included 60 newborns in which CHD was diagnosed in the prenatal period on the basis of fetal echocardiography. The control group consisted of 200 healthy newborns. All patients from the study group suffered from severe combined heart defects, most of which needed urgent cardiosurgical treatment. However, significant differences in the gestational age and birth weight between the groups were a weak point of the study. On the basis of the NT-proBNP cord blood assay, the authors showed significantly higher concentrations of the marker in newborns with CHD. Additionally, NT-proBNP concentrations in cord blood were significantly higher in patients with a functional single ventricle. Although there were statistically significant differences in NT-proBNP concentrations between healthy newborns and those with $\mathrm{CHD}$, the results in both groups overlapped considerably, which meant that the single cord blood assay did not enable clear identification of sick newborns. The NT-proBNP level was evaluated again in 54 patients between the $3^{\text {rd }}$ and $10^{\text {th }}$ day of life, and NT-proBNP was found to increase compared to cord blood levels in all patients with heart defects.

In our study, clearly elevated NT-proBNP concentrations were observed in newborns with combined heart defects compared to both the control group and newborns with simple shunts. None of the healthy newborns had a NT-proBNP concentration $>3000 \mathrm{pg} / \mathrm{mL}$, whereas 26 of the newborns with CHD did.

Both BNP and NT-proBNP have been studied in the context of the identification and evaluation of degree of $\mathrm{HF}$ in several pediatric studies. ${ }^{4,10,20,28-31}$ Although the studies encompass a small number of patients and include variable heart diseases in children, the results seem to be the same: Regardless of etiology (congenital defect, metabolic disorder, inflammation, ischemia, or primary heart muscle disease), natriuretic peptide concentrations increase in direct proportion to the severity of HF symptoms. In a retrospective study including 36 children with dilated cardiomyopathy, Rusconi et al. evaluated the relationship between HF symptom intensity and NT-proBNP serum concentrations. ${ }^{32}$ For each patient, there was a clear relationship between the changes in NT-proBNP and their functional class assessed using New York Heart Association (NYHA)/ Ross classification. Similar results were obtained by Mangat et al. in a study of 48 children with HF secondary to left ventricle systolic dysfunction. ${ }^{31}$ A progressive increase of NT-proBNP together with an increase in functional NYHA/Ross classification scores was observed.

The abovementioned studies focused on infants and children. However, none of the studies evaluated the correlation between natriuretic peptides and clinical HF scoring in newborns with heart diseases. Furthermore, different researchers used different scales and classification systems to evaluate the severity of HF in infants and children since there is no consensus on which scale best reflects the condition of the circulatory system in pediatric patients. ${ }^{33}$ Taking these facts into consideration, in our study, patients were evaluated independently according to 2 different classifications, which seem to be used most often in the existing literature. Each newborn in the study group was evaluated according to the Ross classification score for heart failure in children ${ }^{11}$ and the Reithmann's pediatric heart failure score. ${ }^{13}$ In order to ensure that both classification systems reliably evaluated heart efficiency, we compared their results with echocardiographic hemodynamic significance evaluation. In the study group, both the Ross classification and Reithmann's score correctly reflected the hemodynamic disturbances established with echocardiographic examination. Subsequently, we evaluated the correlation between NT-proBNP level and HF degree estimated according to each of the 2 classifications. A significant correlation was revealed between NT-proBNP level and HF degree evaluated according to the Ross classification score, and an even stronger significant positive correlation was observed using Reithmann's score. The vNT-proBNP level showed good correlation with clinical parameters of HF in newborns with CHD, similar to other age groups.

According to recently conducted studies, the diagnostic usefulness of BNP and NT-proBNP levels in newborns and infants with CHD might be significant. However, this has not been definitively confirmed, as only a few studies have evaluated natriuretic peptides as cardiovascular markers in this age group. From a theoretical point of view, BNP and NT-proBNP appear promising, especially in the field of neonatal intensive care. ${ }^{22}$ The idea of using BNP and NT-proBNP levels as a screening tool to identify newborns with heart defects has received recognition. ${ }^{21,22,34,35}$ Parents or legal guardians of newborns showing elevated BNP or NT-proBNP levels would then receive consultation with a cardiologist, and the newborns would undergo additional tests (i.e., echocardiography), in accordance with international guidelines for adult patients. ${ }^{3}$

There are also a few recent studies worth mentioning that have reported a role of NT-proBNP in PDA and bronchopulmonary dysplasia (BPD). Weisz et al. published a broad review on the utility of this biomarker in dealing with PDA in infants; however, they acknowledge that future investigation is still needed. ${ }^{36}$ The latest idea is to use NT-proBNP level not only for diagnosis, but also as a predictive marker of therapeutic response in PDA. ${ }^{37}$ As for $\mathrm{BPD}$, Xiong et al. published a systematic review concluding that NT-proBNP and BNP levels may be useful for the diagnosis and management of infants with BPD-pulmonary hypertension. ${ }^{38}$

\section{Limitations}

The serum concentration of NT-proBNP was determined using the CARDIAC proBNP immunoassay on a Cobas h232 analyzer, and the main limitation of this 
study is the relatively narrow measurement range of this device. The device can precisely determine NT-proBNP values only in the range of $60-3000 \mathrm{pg} / \mathrm{mL}$; results outside this range are only shown as $<60 \mathrm{pg} / \mathrm{mL}$ or $>3000 \mathrm{pg} / \mathrm{mL}$. Therefore, it is not possible to determine the mean or median of the results obtained.

\section{Conclusions}

There are statistically significant differences in NTproBNP concentrations in newborns with heart defects compared to healthy subjects. In newborns with heart diseases, NT-proBNP concentration is associated with the type of heart defect (simple shunt or combined defects), hemodynamic significance of the defect, LVEF, and clinical intensity of the disease. Evaluation of NT-proBNP level might be useful as a screening tool for the identification of newborns at risk of a heart disease and for identifying the need for urgent cardiologic consultation. Serial measurements of NTproBNP level could be useful for monitoring hemodynamic disturbances in newborns with heart diseases. However, future investigations are needed to confirm this.

\section{ORCID iDs}

Agata Tarkowska (1) https://orcid.org/0000-0001-9369-4213

Wanda Furmaga-Jabłońska (D) https://orcid.org/0000-0002-6006-7683

\section{References}

1. Kawalec W, Kubicka K. Choroby układu krążenia. In: Kubicka K, Kawalec W, eds. Pediatria. Vol. 1. 3rd ed. Warszawa, Poland: PZWL; 2008:270-339.

2. Soongswang J, Durongpisitkul K, Nana A, et al. Cardiac troponin T: A marker in the diagnosis of acute myocarditis in children. Pediatr Cardiol. 2005;26(1):45-49. doi:10.1007/s00246-004-0677-6

3. Dickstein K, Cohen-Solal A, Filippatos G, et al; ESC Committee for Practice Guidelines (CPG). ESC Guidelines for the diagnosis and treatment of acute and chronic heart failure 2008: The Task Force for the Diagnosis and Treatment of Acute and Chronic Heart Failure 2008 of the European Society of Cardiology. Developed in collaboration with the Heart Failure Association of the ESC (HFA) and endorsed by the European Society of Intensive Care. Eur Heart J. 2008;29(19):2388-2442. doi:10.1093/eurheartj/ehn309

4. Mir TS, Marohn S, Laer S, Eiselt M, Grollomus O, Weil J. Plasma concentrations of $\mathrm{N}$-terminal pro-brain natriuretic peptide in control children from the neonatal to adolescent period and in children with congestive heart failure. Pediatrics. 2002;110(6):e76. doi:10.1542/ peds.110.6.e76

5. Koch A, Zink S, Singer H. B-type natriuretic peptide in paediatric patients with congenital heart disease. Eur Heart J. 2006;27(7):861-866. doi:10.1093/eurheartj/ehi773

6. Jeffires JL, Chang AC. Neurohormonal axis and natriuretic peptides in heart failure. In: Chang AC, Towbin JA, eds. Heart Failure in Children and Young Adults. Philadelphia, USA: Elsevier Inc.; 2006:85-95.

7. Bionda C, Bergerot C, Ardail D, et al. Plasma BNP andNT-proBNP assays by automated immunoanalyzers: Analytical and clinical study. Ann Clin Lab Sci. 2006;36(3):299-306. PMID:16951271

8. Piechota W. N-końcowy propeptyd natriuretyczny typu B (NT-proBNP) - znaczenie w kardiologii. Warszawa, Poland: Roche Diagnostics Polska; 2005.

9. Cowley CG, Bradley JD, Shaddy RE. B-type natriuretic peptide levels in congenital heart disease. Pediatr Cardiol. 2004;25(4):336-340. doi:10.1007/s00246-003-0461-z
10. Nir A, Bar-Oz B, Perles Z, Brooks R, Korach A, Rein AJ. N-terminal pro-B-type natriuretic peptide: Reference plasma levels from birth to adolescence. Elevated levels at birth and in infants and children with heart diseases. Acta Paediatr. 2004;93(5):603-607. doi:10.1111/ j.1651-2227.2004.tb02984.x

11. Ross RD. Grading the graders of congestive heart failure in children. J Pediatr. 2001;138(5):618-620. doi:10.1067/mpd.2001.115707

12. Ross RD, Bollinger RO, Pinsky WW. Grading the severity of congestive heart failure in infants. Pediatr Cardiol. 1992;13(2):72-75. doi:10.1007/ BF00798207

13. Reithmann C, Reber D, Kozlik-Feldman R, et al. Post-receptor defect of adenyl cyclase in severely failing myocardium from children with congenital heart disease. Eur J Pharmacol. 1997;330(1):79-86. doi:10. 1016/s0014-2999(97)10131-5

14. Maisel AS, Krishnaswamy P, Nowak RM, et al; Breathing Not Properly Multinational Study Investigators. Rapid measurment of B-type natriuretic peptide in the emergency diagnosis of heart failure. NEng JMed. 2002;347:161-167. doi:10.1056/NEJMoa020233

15. Troughton RW, Frampton CM, Yandle TG, Espiner EA, Nicholls MG, Richards AM. Treatment of heart failure guided by plasma aminoterminal brain natriuretic peptide (N-BNP) concentrations. Lancet. 2000;355(9210):1126-1130. doi:10.1016/s0140-6736(00)02060-2

16. Lubien E, DeMaria A, Krishnaswamy $P$, et al. Utility of B-natriuretic peptide in detecting diastolic dysfunction: Comparison with Doppler velocity recordings. Circulation. 2002;105(5):595-601. doi:10.1161/ hc0502.103010

17. Redfield MM, Rodeheffer RJ, Jacobsen SJ, Mahoney DW, Bailey KR, Burnett JC Jr. Plasma brain natriuretic peptide to detect preclinical ventricular systolic or diastolic dysfunction: A community-based study. Circulation. 2004;109(25):3176-3181. doi:10.1161/01.CIR.0000 130845.38133.8F

18. Anand IS, Fisher LD, Chiang YT, et al. Changes in brain natriuretic peptide and norepinephrine over time and mortality and morbidity in the Valsartan Heart Failure Trial (Val-HeFT). Circulation. 2004; 107(9):1278-1283. doi:10.1161/01.cir.0000054164.99881.00

19. Westerlind A, Wahlander $H$, Lindstedt $G$, et al. Clinical signs of heart failure are associated with increased level of natriuretic peptide types $B$ and $A$ in children with congenital heart defects or cardiomyopathy. Acta Paediatr. 2004;93(3):340-345. doi:10.1080/08035250410022756

20. Geiger R, Hammerer-Lercher A, Url C, Schweigmann U, et al. NT-proBNP concentrations indicate cardiac disease in pediatric patients. Int J Cardiol. 2007;123(1):63-65. doi:10.1016/j.ijcard.2006.11.087

21. Law YM, Hoyer AW, Reller MD, Silberbach M. Accuracy of plasma B-type natriuretic peptide to diagnose significant cardiovascular disease in children: The Better Not Pout children! study. J Am Coll Cardiol. 2009;54(15):1467-1475. doi:10.1016/j.jacc.2009.06.020

22. Cantinotti M, Storti S, Ripoli A, et al. Diagnostic accuracy of B-type natriuretic hormone for congenital heart disease in the first month of life. Clin Chem Lab Med. 2010;48(9):1333-1338. doi:10.1515/CCLM.2010.251

23. Emdin $M$, Vittorini S, Passino C, Clerico A. Old and new biomarkers of heart failure. Eur J Heart Fail. 2009;11(4):331-335. doi:10.1093/eurjhf/ hfp035

24. Kunii $Y$, Kamada M, Ohtsuki S, et al. Plasma brain natriuretic peptide and the evaluation of volume overload in infants and children with congenital heart disease. Acta Med Okayama. 2003;57(4):191-197. doi:10.18926/AMO/32809

25. El-Khuffash A, Molloy EJ. The use of $\mathrm{N}$-terminal-pro-BNP in preterm infants. Int J Pediatr. 2009;2009:175216. doi:10.1155/2009/175216

26. Hopkins WE, Chen Z, Fukagawa NK, Hall C, Knot HJ, LeWinter MM. Increased atrial and brain natriuretic peptides in adults with cyanotic congenital heart disease: Enhanced understanding of the relationship between hypoxia and natriuretic peptide secretion. Circulation. 2004;109(23):2872-2877. doi:10.1161/01.CIR.0000129305.25115.80

27. Lechner E, Wiesinger-Eidenberger G, Wagner O, et al. Amino terminal proB-type natriuretic peptide levels are elevated in the cord blood of neonates with congenital heart defect. Pediatr Res. 2009;66(4): 466-469. doi:10.1203/PDR.0b013e3181b3aee4

28. Hammerer-Lercher A, Neubauer E, Muller S, et al. Head-to-head comparison of $\mathrm{N}$-terminal pro-brain natriuretic peptide, brain natriuretic peptide and $\mathrm{N}$-terminal pro-atrial natriuretic peptide in diagnosing left ventricular dysfunction. Clin Chim Acta. 2001;310(2):193-197. doi:10.1016/s0009-8981(01)00578-2 
29. Cohen S, Springer C, Avital A, et al. Amino-terminal pro-brain-type natriuretic peptide: Heart or lung disease in pediatric respiratory distress? Pediatrics. 2005;115(5):1347-1350. doi:10.1542/peds.2004-1429

30. Nir A, Nasser N. Clinical value of NT-ProBNP and BNP in pediatric cardiology. J Card Fail. 2005;11(5 Suppl):76-80. doi:10.1016/j.cardfail. 2005.04.009

31. Mangat J, Carter C, Riley G, Foo Y, Burch M. The clinical utility of brain natriuretic peptide in paediatric left ventricular failure. Eur J Heart Fail. 2009;11(1):48-52. doi:10.1093/eurjhf/hfn001

32. Rusconi PLD, Ratnasamy C, Mas R, Harmon WG, Colan SD, Lipshultz SE. Serial measurements of serum NT-proBNP as markers of left ventricular systolic function and remodeling in children with heart failure. Am Heart J. 2010;160(4):776-783. doi:10.1016/j.ahj.2010.07.012

33. Altman CA, Kung G. Clinical recognition of congestive heart failure in children. In: Chang AC, Towbin JA, eds. Heart Failure in Children and Young Adults. Philadelphia, USA: Elsevier Inc.; 2006:201-208.
34. Nir A, Lindinger A, Rauh M, et al. NT-pro-B-type natriuretic peptide in infants and children: Reference values based on combined data from four studies. Pediatr Cardiol. 2009;30(1):3-8. doi:10.1007/s00246008-9258-4

35. El-Khuffash A, Molloy EJ. Are B-type natriuretic peptide (BNP) and N-terminal-pro-BNP useful in neonates? Arch Dis Child Fetal Neonatal Ed. 2007;92(4):F320-F324. doi:10.1136/adc.2006.106039

36. Weisz DE, McNamara PJ, El-Khuffash A. Cardiac biomarkers and haemodynamically significant patent ductus arteriosus in preterm infants. Early Hum Dev. 2017;105:41-47. doi:10.1016/j.earlhumdev.2016.12.007

37. Hu Y, Jin H, Jiang Y, Du J. Prediction of therapeutic response to cyclooxygenase inhibitors in preterm infants with patent ductus arteriosus. Pediatr Cardiol. 2018;39(4):647-652. doi:10.1007/s00246-018-1831-x

38. Xiong T, Kulkarni M, Gokulakrishnan G, Shivanna B, Pammi M. Natriuretic peptides in bronchopulmonary dysplasia: A systematic review. J Perinatol. 2020;40(4):607-615. doi:10.1038/s41372-019-0588-2 